\section{INDUSTRIAL UTILIZATION OF AGRICULTURAL PRODUCTS AND SEAWEED}

\begin{abstract}
$\mathrm{A}$ COLLOQUIUM on "The Industrial Utilization of Agricultural Products and of Seaweed", organised by Cumann Ceimicidhe na hEireann (Irish Chemical Association) and the Dublin Section of the Royal Institute of Chemistry, was held in Dublin during July 2-3. The first chemistry conference to be held in Ireland, it was attended by chemists from all parts of that country as well as by a number from Great Britain.

The purpose of the colloquium was the examination of the present knowledge of the chemistry of various agricultural products and seaweed with the view of focusing attention on their potentialities as sources of raw materials for industrial purposes, and this aim was commended by the Tánaiste, Mr. Sean Lemass, Minister for Industry and Commerce, in his address when he formally opened the colloquium and welcomed the visiting speakers.
\end{abstract}

At the first session, which was devoted to a general survey of the subject, Dr. J. L. Simonsen, director of the Colonial Products Research Council, opened the proceedings with an address on "Agricultural Products and the Chemical Industry", in which he stressed the possibilities of sucrose as the basis of a new chemical industry on account of the fact that it may, with comparative ease, be converted into its octacetate, to its hydrogenation products mannitol and sorbitol, to the anhydrides of these, to lactic acid and to lævulinic acid, all of which substances have useful industrial applications. For example, the octacetate may be incorporated with laminated glass or with synthetic resins; sorbitol by microbiological oxidation can be converted to $l$-sorbose, which is the starting-point for the manufacture of vitamin $\mathrm{C}$; the dehydration products of mannitol and sorbitol may be employed in the preparation of plasticizers and resins; lactic acid is used in the leather industry, and it also provides a convenient route to the preparation of acrylic esters; from lævulinic acid, substances which show promise of being of therapeutic value may be obtained, while the sodium salt of the acid is an 'anti-freeze' compound with significant advantages over other substances used for a similar purpose. A further variety of useful compounds may be obtained from sucrose by fermentation processes.

In the discussion which followed, Mr. W. V. Griffiths spoke on Irish fruits, the utilization of which in strictly chemical processes he considered likely to remain unimportant. Prof. G. T. Pyne dealt with industries based on casein and lactose, and Dr. H. Kennedy and Dr. H. A. Lafferty treated the subject from economic aspects.

"Seaweed" was the subject for the second session, and Prof. J. B. Speakman, professor of textile industries, University of Leeds, opened the discussion with a lecture on "The Production, Properties and Uses of Seaweed Rayon". After describing the extraction of alginic acid from seaweed, he gave an account of the work which led to the preparation of a calcium alginate solution suitable for spinning to fibre of a quality capable of being woven into fabric. This fabric goes into solution when washed in soap or soda; but the solubility of the calcium alginate fibre, at first so surely a damning feature, has been turned to such good account as to become its most valuable property. By embroidering on alginate fabric or incorporating alginate fibre with other fibres in various ways, weaving the resulting thread, and in each case eventually removing the-alginate by washing, it has been possible to produce such materials as lace, fabrics which are self-sealing in rain or water, crêpes, artificial astrakhan and woollen cloth of extremely light texture. Prof. Speakman exhibited a large number of materials made by this ingenious 'disappearing thread' technique.

Prof. T. Dillon discussed the industrial possibilities of agar, carrageen mucilage and algin, Mr. D. T. Flood dealt with seaweed as a raw material in industry, Dr. T. Twomey described the processing of seaweed mucilages, and Mr. J. P. Twohig spoke on wool as an agricultural product, with special reference to its incorporation with seaweed-based rayon.

At the final session, with "Carbohydrates" as the subject, Prof. E. L. Hirst, director of the Chemical Laboratories, The University, Manchester, who has just been appointed to the new Forbes chair of organic chemistry at Edinburgh, speaking on "The Utilization of Carbohydrates", reviewed the more recent research work on cellulose, starch and sugar, and discussed the results obtained in relation to the possibilities of using these substances as raw materials. Degradation of cellulose from woody materials, by newer methods of hydrolysis, for the preparation of readily fermentable sugar solutions, would appear to lend itself to large-scale development. Potential new methods of utilization of starch, and the more exact control of existing manufacturing processes based on starch, become possible as a result of the newer knowledge of the starch granule. Uses may be found for each of the two structurally different major com. ponents, amylose and amylopectin, but large-scale separation of the granule into these requires further research. The interesting fact that the so-called 'waxy' starches, for example, waxy maize starch, contain amylopectin only, points to the possibility of the control of the composition of the starch granule by plant breeding. Sucrose, once the present supply difficulties have been overcome, can be considered as the starting point for an organic chemical industry because of the wide range of substances of industrial importance which can now be derived from it.

The contributors to the discussion were Dr. D. W. Kent-Jones, who gave information on the processing of flour for the preparation of amino-acids, Mr. G. A. C. Wilkin, who spoke on modern trends in the beet sugar industry, Dr. van der Le日, who discussed the industrial utilization of potatoes, and Mr. H. I. O'Reilly, who directed attention to the importance of some products of yeast fermentation.

Dr. V. C. Barry, president of the Irish Chemical Association, and Dr. A. G. G. Leonard, chairman of the Dublin Section of the Royal Institute of Chemistry, presided at the sessions.

There were three social events connected with the colloquium. On the evening of July 1, the members and their friends were entertained by the Irish Sugar Company at a reception in the Shelbourne Hotel, and provided with an opportunity of meeting in very pleasant circumstances before the serious business of the programme began. On Thursday afternoon, July 3, the President of Ireland and Mrs. O'Kelly showed their interest in the purpose of the colloquium by conferring on its members the honour of being received by them at their official residence in the Phœenix Park. There could have 
been no more fitting conclusion to the activities than the 'party', consisting of a reception and dance, given by Imperial Chemical Industries, Ltd., in the Royal Hibernian Hotel on the evening of July 3 ; it was so thoroughly enjoyable as to make it certain that the visitors would carry away with them very happy recollections of their stay in Dublin.

G. H'. O'Sullivan

\section{DISPLACEMENT CHROMATO- GRAPHY ON CATION-EXCHANGE MATERIALS}

\section{By J. R. BENDALL, S. M. PARTRIDGE}

R. G. WESTALL

Low Temperature Station for Research in Biochemistry and Biophysics, Cambridge

TN recent years there have been many attempts to 1 utilize the properties of the newer synthetic ionexchange reagents for the separation of bases and amino-acids, but the application of truly chromatographic procedures has met with only partial success. In the course of the present investigation, it became clear that very sharp separations could be obtained on cation-exchange columns by the utilization of a strong base to displace others in the system. It was found that such a procedure could be reduced to the terms of the 'displacement development' principle introduced by Tiselius' for separations on adsorption columns of carbon or alumina, and for this reason we have made use of the theoretical background developed by this worker and his colleagues.

In essentials the method is as follows. The mixture of bases to be separated is introduced on to a column containing the cation-exchange reagent, and the components of the mixture are displaced down the column by the application of a solution of a base that is more strongly retained than the others in the mixture. In this way, once a flowing equilibrium has been established, the less strongly retained bases are successively displaced by bases having a stronger affinity for the ion-exchanger, and the components of the mixture pass down the column in a series of discrete bands, finally flowing from it in an order dependent upon the degree to which they are retained. In order to follow the changes in composition of the effluent, continuous measurements are made of two of the physical properties of the solution: electrical conductivity and hydrogen ion concentration.

In the present form of the apparatus, the adsorption column is of glass and is mounted in a 'Perspex' block. The block is accurately centred over an assembly consisting of a conductivity-cell, a valve for regulating the flow of liquid through the apparatus and a glass-electrode cell, all of which are made of 'Perspex'.

The behaviour of bases and ampholytes on the ion-exchange column may be expressed in the form of the familiar 'adsorption isotherm' in which the amount of substance adsorbed per gm. of adsorbent is plotted against the concentration of the solution. For the determination of such isotherms, a column is packed with a known weight of ion-exchanger, and a solution of the substance under test is passed through it. The effluent at first consists of pure solvent only, but when the retention front reaches the bottom of the column and a steady state is reached, the solution flowing from the column is of the same concentration as that supplied to it. The volume of pure solvent is characteristic for each solute and is termed the 'retention volume' $(v)$. The weight of solute retained is then $v \times c$, where $c$ is the concentration of the solution entering the column. If the column is initially wet with solvent, a small correction must be applied for the initial volume of. solvent contained in it. The isotherms so determined are not necessarily identical with those determined by the classical methods, or with those calculated from titration curves, since a solution at constant concentration flows into the column at a finite rate. However, this method has been adopted, since the separation experiments are conducted under similar conditions.

The retention data in the curves of Figs. 1 and 2 refer to the cation-exchange resin 'Zeo-Karb. 215' (obtainable from the Permutit Co., Ltd., London): This was used as a sieved powder ( $80-100$ mesh). In Fig. 1 the experimentally determined retention isotherms of a number of bases and amino-acids are shown.

The amount of base in millimols $(\varepsilon)$ retained per gm. of 'Zeo-Karb.' (water content, 21 per cent) is plotted against the concentration in millimols per ml., with the exeeption of barium hydroxide, the isothorm of which is plotted in terms of milliequivalents instead of millimols. The gradients of the isotherms at low values of the concentration are very steep, and as the curves are in fact titration curves, they do not fit either the Freundlich or Langmuir equations. It was found that the amount of solute retained was independent of the rate of flow of the solution over a fairly wide range, and in most cases a rate of 70-100 ml. per hour was employed with columns $9 \mathrm{~mm}$. in internal diameter.

A typical separation experiment is shown in Fig. 2. A mixture of 3.0 millimols of glycine and 3.4 millimols

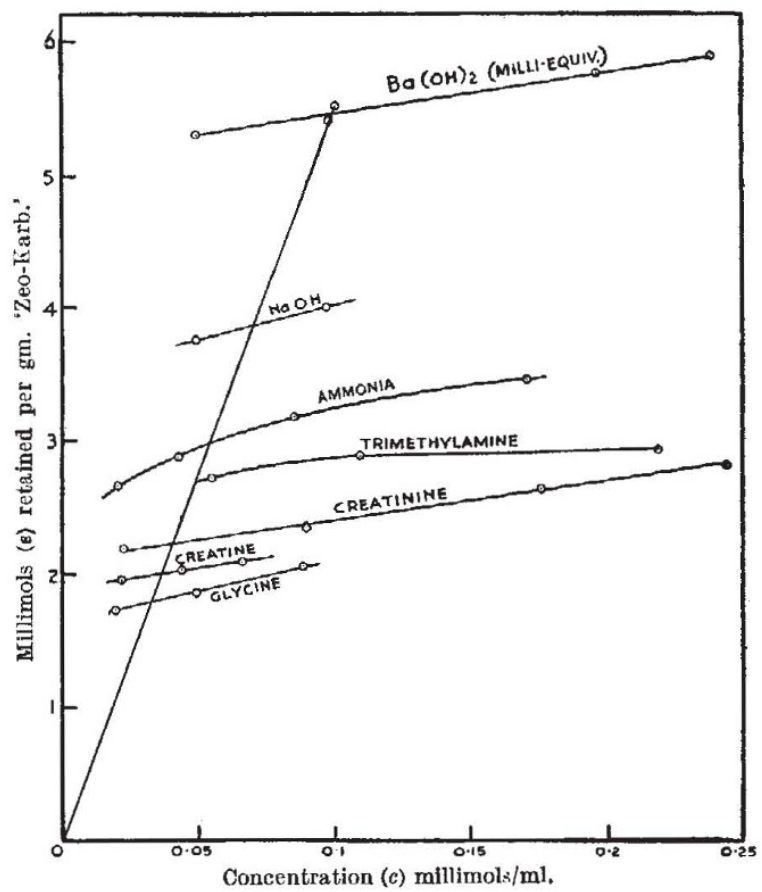

Fig. 1 